\title{
A Forensic View of Pesticide Poisonings in Brazil
}

\author{
Bruno Sabino, Hannah Rozenbaum and Adriana Oliveira \\ Instituto de Criminalística Carlos Éboli [ICCE] \\ Brazil
}

\section{Introduction}

Pesticides are substances extensively used in the country or in town for preventing, destroying, repelling or mitigating any pest. These groups of substances include different classes of compounds that present different types of toxicity. Although there are benefits to the use of pesticides, there are also drawbacks, such as potential toxicity to humans and other animals. According to the Stockholm Convention on Persistent Organic Pollutants, 10 of the 12 most dangerous and persistent organic chemicals are pesticides.

Because of their potential toxicity, these substances are commonly used as poisons in homicides, homicides attempts, suicides and also in cases of crime against animals. In forensic laboratories, foodstuffs and drinks used to cause the poisoning are usually analyzed to determine the presence of any potential toxic substance in the material. In this chapter we will explore the forensic aspects evolving the use of pesticides in crimes against life.

Primarily, we will present a database of the types of pesticides found in our forensic laboratories. We will analyze these data to create a pesticide poisoning profile in Brazil, determining the classes of pesticides used by region; the types of matrices used to cause the poisoning, and the incidence of death associated to the poisoning.

After tracing the main types of pesticides used in suspected cases of poisoning analyzed in forensic laboratories, we will be able to discuss the acute toxicity of the different types of pesticides currently associated with poisonings. We can use the literature to preview the acute effects of the ingestion of the foodstuffs and the drinks contaminated with the pesticides. Besides, we can determine the potential of causing death due to the ingestion of the contaminated material.

Other important aspect to be discussed in this chapter is the legal regulation of pesticides trade in Brazil. The Brazilian law is restrictive in the regulation of pesticides use and sale. The permission of pesticides use is specific for the culture exploited and for the class of pesticide released. Besides, the purchase of these compounds, in regard to the most toxic ones, are restricted to the agronomist engineer and requires the presentation of prescription. The legal aspects will alert us about the importance of the fiscalization to inhibit the indiscriminate use of these substances in crimes.

Finally, we will detail the forensic analytical chemistry of pesticides in diverse matrices currently found in forensic institutes. In Brazilian Institutes, the techniques used in forensic chemistry in pesticides analysis most often includes the simple Thin Layer Chromatography 
(TLC) with confirmation by using a Gas Chromatography coupled to Mass Spectrometry (GC-MS) technique. In some Brazilian advanced Institutes and in developed countries, other sophisticated methods can be used, such as: Liquid Chromatography coupled to Mass Spectrometry (LC-MS), and Gas Chromatography coupled to Mass Spectrometry in tandem (CG-MS-MS). Alternatively, our group has recently published a simple liquid-liquid extraction step followed by an enzymatic analysis using a freeze-dried preparation of the enzyme acetylcholinesterase obtained from rat brain to detect the presence of aldicarb and other cholinesterase inhibitors in meat products for forensic purposes. We will also present some confirmatory techniques that can be used in a portable presentation, like Fourier Transform Infrared Spectroscopy (FTIR), and Raman Spectroscopy. We will discuss the different types of sample preparation to obtain the best clean-up of the sample. Besides, we will list and discuss the main advantages and disadvantages of the principal instrumental methods used to detect and quantify the pesticides in foodstuffs and drinks matrices.

In conclusion, this chapter will discuss the main aspects of forensic toxicology involving the pesticides and intends to be an alert for other countries that faces the growing problem of pesticides poisoning.

\section{Pesticide poisoning around the world}

The first global estimates of the extent of pesticide poisoning were published in 1990 by the World Health Organisation (WHO) (WHO, 1990). Based on extrapolations from limited data, it was estimated that 3 million cases of pesticide poisonings annually occurred worldwide, with 220,000 deaths; the majority of which are intentional (Konradsen, van der Hoek et al., 2003).

The WHO estimates, based on data from 2001, that 849,000 people die globally from selfharm each year (WHO, 2002). How many of these cases are a result of poisoning with pesticides is not known. However, poisoning is the most common form of fatal self-harm, such as suicides, in rural Asia, accounting for over $60 \%$ of all deaths (Somasundaram \& Rajadurai, 1995; Phillips, Li et al., 2002; Joseph, Abraham et al., 2003) and is of far greater importance than hanging and other physical forms of self-harm. Furthermore, a review of poisoning studies reveals that pesticides are the most common way of self-poisoning in many rural areas and are associated with a high mortality rate (Eddleston, 2000). A recent national survey, in the year 2000, in Bangladesh showed that $14 \%$ of all deaths (3971 of 28,998 ) of women between 10 and 50 years of age were due to self-poisoning; the majority of which used pesticides (Yusuf, Akhter et al., 2000). The problem is particularly severe in Sri Lanka (Berger, 1988; Van der Hoek, Konradsen et al., 1998), where pesticide poisoning was the commonest cause of hospital death in six rural districts in 1995 (Sri_Lanka, 1995). In many countries, the widespread availability of acutely toxic pesticides used in agriculture has made the selection of pesticides as the agents of choice for self-harm well known to both healthcare workers and public-health authorities (Nalin, 1973; Kasilo, Hobane et al., 1991; Daisley \& Hutchinson, 1998).

A retrospective study, covering the period from January 2000 to December 2005, based on autopsies samples sent to the Laboratory of Forensic Toxicology in the National Institute of Health in Morocco shows that, from total of 3104 analyses performed in the laboratory, 130 cases $(4.19 \%)$ were related to fatal pesticide poisoning (El Cadi, Mezzane et al., 2008).

In the Morroco survey, fatal pesticide intoxications were classified as suicide in $23.1 \%$ of cases, uncertain in $75 \%$ of cases, and accidental in only $1.5 \%$ of fatal poisonings. The average 
of age in all cases was $28 \pm 15$ years old. The highest frequency of pesticide poisoning (40.8\%) was found for those 20-39 years old. The difference between genders in fatal pesticide poisoning was small: $51 \%$ male and $48 \%$ female. This difference may be explained by the predominance of suicides for females. Another study confirms this result (Abdullat, Hadidi et al., 2006). The Samples were sent for toxicological analysis from the majority of Moroccan cities, including urban areas and rural regions; however, the best represented city was Rabat with 55 cases $(42.3 \%)$. This representation may be explained by the time of storage of samples from other cities. The data show that insecticides were the most frequent cause of fatal pesticide poisoning (75.2\%), followed by aluminium phosphide (21.5\%). Among insecticides, organophosphorus compounds were the most frequent $(55.4 \%)$, followed by carbamates $(15.4 \%)$ and organochlorine $(4.6 \%)$. One case of pyrethroid and one case of coumarinic anticoagulant were found (El Cadi, Mezzane et al., 2008).

The incidence of pesticide poisoning in Morocco in the period between 2000 and 2005 was $4.19 \%$, which is compared to other series (Casey \& Vale, 1994; Vougiouklakis, Boumba et al., 2006; Soltaninejad, Faryadi et al., 2007). However, there is a lack of systematic study and declaration in Morocco, especially in rural areas. This lack makes the discussion of the results difficult and may underestimate the number of fatal pesticide poisonings. The data show that pesticides are commonly used for suicide. This result is in accordance with previous studies (Eddleston \& Phillips, 2004; Nesime, Lokman et al., 2004; Vougiouklakis, Boumba et al., 2005). In fact, in Sri Lanka, $90 \%$ of suicides are due to deliberate pesticide ingestion (Manuel, Gunnell et al., 2008), and the WHO reports that pesticides are now the most common method of suicide worldwide (Testud \& Grillet, 2007).

In Coimbra, Portugal, a three-year retrospective study was performed between January 2000 and December 2002 in the Forensic Toxicology Laboratory, which received 639 blood samples for pesticide-analysis. In 2000, out of a total of 149 analysis requests, 30 cases were positive, $63.3 \%$ from male individuals and $36.7 \%$ from female individuals. In 2001, the analysis requests increased (240), as did the number of positive cases (43), 74.4\% from male individuals and $25.6 \%$ from female individuals. In 2002, the total cases analysed increased to 250 , with 38 positive results $(73.6 \%$ from male individuals and $26.4 \%$ from female individuals) (Teixeira, Proenca et al., 2004).

According to this study, among the pesticides, organophosphorus insecticides still constitute the most important class detected in forensic intoxications, representing $63 \%$ of the total positive cases, followed by herbicides, with $33 \%$ of the positive results. Quinalphos is the most common organophosphorus insecticide, which was present in 32 of the 111 positive cases, followed by the herbicide paraquat, which was detected in 31 cases (Teixeira, Proenca et al., 2004).

\subsection{Pesticide poisoning in Brazil}

In the 2009 census, the population of Brazil reached 194,400,000, the 5th-largest country in population in the world. Brazil is administratively divided into 26 Federal States and one Federal District. Rio de Janeiro State, with about 16,000,000 people (2010), represents almost $8 \%$ of the national population and $0.5 \%$ of the national territory area.

In 2005, Brazil was 6th in the world in the rate of homicide of the entire population, counting 25.8 homicides per hundred-thousand inhabitants. In 1997, Rio de Janeiro had the highest homicide index in the country (66.3), and in 2007, it had the 4th-highest index of 52,2 , much higher than the national index and higher than that of the country with the highest index, El Salvador, with a 50,1 index (Waiselfisz, 1998). 
In 2003, Brazil created a computerised on-line system to transfer in real time the organophosphorus- and carbamates-intoxication information from Legal Medical Institutes (IML, acronym from the Portuguese, Institutos Médicos Legais), known as the National System of Toxico-Pharmacology Information (SINITOX, acronym from Portuguese, Sistema Nacional de Informações Fármaco-Toxicológicas) (SINITOX, 2008).

Table 1 shows the total number of general pesticide-intoxication cases in Brazil, according to SINITOX, involving pesticides used to protect agriculture and horticultural corps against damage, veterinary pesticides, veterinary products and rodenticides (SINITOX, 2008):

\begin{tabular}{|c|c|}
\hline Year & Number of Cases \\
\hline \hline 2004 & 13,942 \\
\hline 2005 & 14,648 \\
\hline 2006 & 15,907 \\
\hline 2007 & 15,377 \\
\hline 2008 & 10,914 \\
\hline
\end{tabular}

Table 1. Number of intoxication cases involving general pesticides in Brazil. Source: (SINITOX, 2008).

The circumstances of these intoxications include individual accident, group accident, environmental accident, occupational accident, therapeutic use, improper medical prescription, self-administration mistake, self-medication, abuse, food ingestion, abortion attempts, suicide attempts or suicide, violence, homicide and ignored cases. The cases with forensic linkage include abortion attempts, suicide attempts or suicide, violence and homicide. Figure 1 shows the percent index with forensic linkage in relation to the total number of cases in Brazil (Table 1) (SINITOX, 2008).

In Rio de Janeiro State, the cases with forensic linkage show the following trend (Figure 2). The overall death rate per the population involving such occurrences is less than $2 \%$, but this index may be underestimated because the deaths without medical assistance when the body is not sent for a health service might not be reported. In fact, the poisoning rates in Brazil are highly underestimated due to under-reporting. According to the Brazilian Ministry of Health, for each reported poisoning, another 50 were not reported. The reasons for not reporting include lack of access to medical care in poor areas, the lack of a precise diagnosis due to the symptoms of pesticide poisoning being similar to the other health problems and the lack of an efficient information transfer system from the hospitals to the National Centre of Toxicological Vigilance, despite the reporting being mandatory (SINITOX, 2008).

In the state of Mato Grosso do Sul, the Brazilian state with the 8th-highest agricultural production (Rebelo, Vasconcelos et al., 2010), 1,355 cases of voluntary or involuntary poisoning were reported to the Integrated Centre of Toxicological Vigilance of the State Health Department from 1992 to 2002, with an average of 123.2 poisonings/year, 176 of which lead to death. The case fatality rate (CFR) was 3 times higher than that of the average states in Brazil (Recena, Pires et al., 2006).

Some studies have shown an association between exposure to pesticides and symptoms of depression, an important factor often linked to suicides and attempts. In Luz, a micro-region of the state of Minas Gerais, which is the 6th-highest agricultural producer in Brazil, a study 


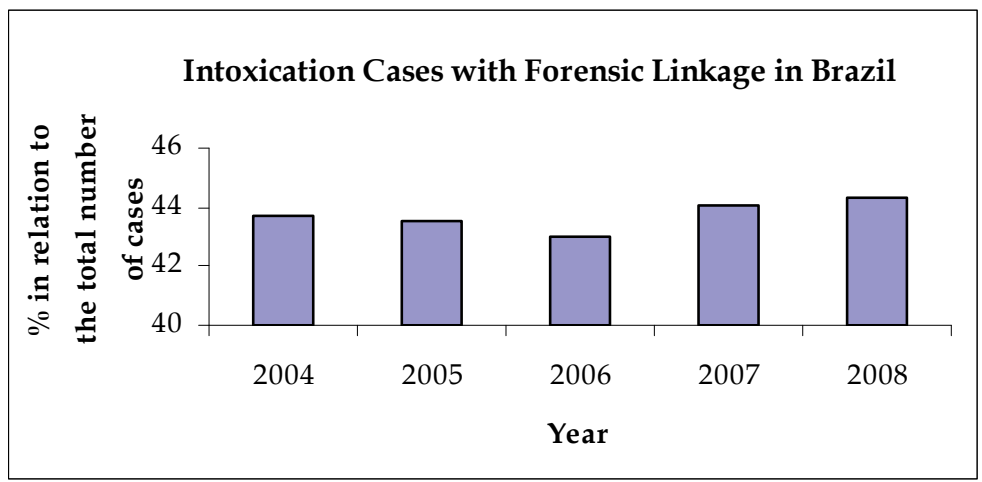

Fig. 1. Intoxication Cases with Forensic Linkage involving pesticides in Brazil

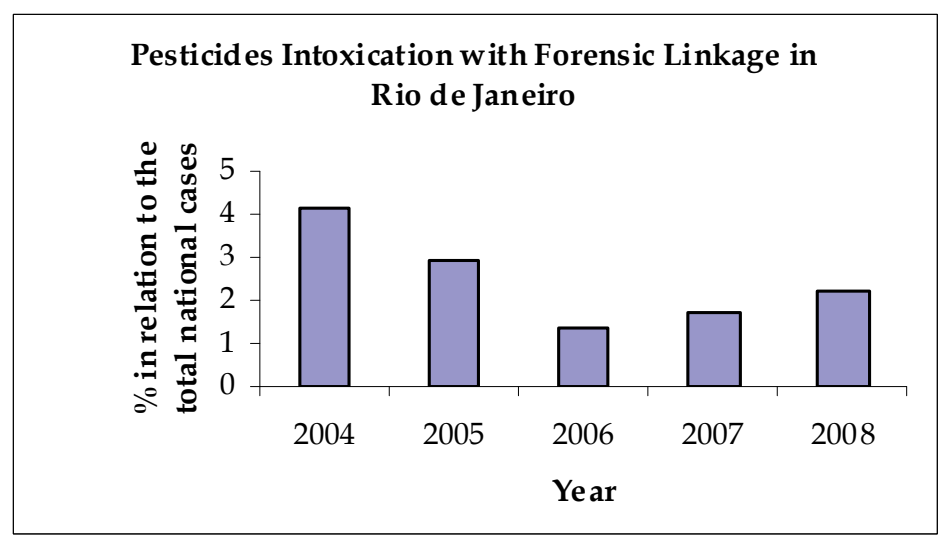

Fig. 2. Trend of cases involving pesticides with forensic linkage in state of Rio de Janeiro

investigated the relationship between poisoning cases and pesticides (Meyer, Resende et al., 2007). From 2000 to 2004, 19 suicides occurred in the region (22.6/100,000 inhab/year), 18 involved male rural workers, and $57.9 \%$ by ingestion of pesticides. A group of 50 residents was interviewed and gave biological samples for analysis. The results show that $98 \%$ of the residents handled pesticides regularly, $72 \%$ had never used any protection equipment, $56 \%$ had never read information sheets, and $40 \%$ presented poisoning values in the analysis results. The number of suicide incidence was more than twice the highest state average in Brazil, and the number of pesticide-poisoning cases was high compared to SINITOX data (Meyer, Resende et al., 2007).

In Rio de Janeiro State, in the case of humans violent deaths and homicides attempts, and crimes against animals and/or to the environment, when the crime is registered to a police department, the victims, in death cases, are sent to the Legal Medical Institute to perform an autopsy and toxicological analysis. The materials associated to the poisoning collected at the crime scene are sent to the Criminalistic Institute for identification and characterisation. 
Rio de Janeiro is not considered to be a typical agricultural state in Brazil and is not among the top ten highest agricultural producers in the country. Despite this fact, the number of intoxication cases involving the use of pesticides is extremely high. Table 2 shows the number of materials examined in the Rio de Janeiro Criminalistic Institute, related to diverse crimes, where the presence of pesticides in the period of 2003 until 2010 was found using numerous analytical methods discussed later in this chapter (data not published):

\begin{tabular}{|c|c|}
\hline Year & Identified Materials \\
\hline \hline 2003 & 77 \\
\hline 2004 & 76 \\
\hline 2005 & 77 \\
\hline 2006 & 71 \\
\hline 2007 & 69 \\
\hline 2008 & 81 \\
\hline 2009 & 78 \\
\hline 2010 & 89 \\
\hline
\end{tabular}

Table 2. Number of materials associated to the poisoning collected at the crime scene that resulted positive in general pesticides analysis in state of Rio de Janeiro.

The slight increase in the number of cases identified in the last three years may be related to the diversification of the analytical techniques used, including enzymatic methods and instrumental analysis.

According to the data available at the Chemical Sector of the Rio de Janeiro Criminalistic Institute and the Rio de Janeiro Police State, out of the 89 investigated cases with positive pesticide identifications in 2010, 10 are related to the irregular commercialisation of the pesticide, 17 are related to crime against animals generally causing domestic-animal deaths, 30 are from materials used in completed suicides, 3 in suicide attempts, 18 are related to homicide attempts, 2 cases are related to the use of pesticide in homicide followed by suicide, and 5 cases have not be determined by the legal guidelines. In the related cases, aldicarb, from carbamate chemical group, was identified 77 times. Other carbamates detected include carbofuran (five times), carbaryl (Rebelo, Vasconcelos et al.) and iprovalicarb (Rebelo, Vasconcelos et al.). Other pesticides identified were second-generation coumarinic derivatives (six cases), picloran (two cases), cipermetrin (two cases), deltametrin (one case), and DDVP (one case). In two cases, the association of two pesticides among the 89 investigated cases with positive pesticide identifications was identified. Aldicarb was present in $78.6 \%$ of all cases, and at least one of the compounds identified was from the carbamate class in $85.4 \%$ of all cases (data not published).

\section{Toxicity of carbamates}

The numerous cases of pesticide poisoning all over the world and in Brazil, especially involving the use of the carbamate compound aldicarb, described in the previously sections, is consistent with the acute toxicity of this substance. In order to understand the lethal capacity of this pesticide we will briefly describe the well known toxicology of the 
carbamates. Then we will describe some studies with human volunteers to highlight the carbamate amount required to cause human death by oral ingestion.

\subsection{Carbamates toxicology}

The primary mode of aldicarb toxicity is cholinesterase inhibition. Carbamate insecticides are known to directly affect the enzyme acetylcholinesterase (AChE), which is associated with the outer surface of membranes. This results in a buildup of acetylcholine (ACh), which acts on the plasma membrane to produce the primary expression of neurotoxicity (Blum \& Manzo, 1985). It is commonly accepted that carbamates interfere with the ability of AChE to break down the chemical transmitter $\mathrm{ACh}$ at synaptic and myoneural junctions, although the precise biochemical mechanism for this interaction remains an object of discussion. It is known, however, that the same mechanism of action is evident in both target and nontarget organisms. Aldicarb and other carbamate insecticides further cause depression of other cholinesterases ("pseudocholinesterases") in the red blood cells and plasma of humans and other vetebrate species, but the degree of inhibition necessary to produce adverse effects in exposed subjects is speculative and the subject of current research (Risher, Mink et al., 1987). The relationship for carbamates between intoxication symptoms and cholinesterase activity was first described in a series of experiments in which brain and plasma ChE activities were determined in rats after propoxur was administered intramuscularly at different dosages. The animals were killed at the moment the first symptoms appeared or at a given time after injection. At dosages that did not produce any noticeable symptoms $(0.25-1.0 \mathrm{mg} / \mathrm{kg})$, the activities of both brain and plasma ChE were reduced by varying amounts, down to about $60 \%$ of the normal level. The dose at which a very slight tremor occurred $(2.0 \mathrm{mg} / \mathrm{kg})$ reduced the brain and plasma ChE activities to $470 \%$ and $49 \%$ of the normal levels, respectively; the animals was killed immediately after this symptom was observed. At higher dosages $(10.0$ and $50.0 \mathrm{mg} / \mathrm{kg}$ ) the degrees of inhibition of both brain and plasma cholinesterase closely followed the severity of the symptoms that were produced, with the brain ChE usually showing $5-15 \%$ greater inhibition than the plasma ChE (Vandekar, Plestina et al., 1971).

Various cholinesterases have also been identified in the brain, liver, pancreas, intestine, heart, and skeletal muscle of mammals and may be distinguished from one another and from AChE ("true cholinesterases") by substrate and inhibitor specificity. Erythrocyte AChE is a more appropriate indicator of the level of $\mathrm{AChE}$ in the central nervous system (CNS) than plasma AChE. Blood ChE generally becomes markedly depressed prior to the onset of cholinergic symptoms, and symptoms do not usually appear until the cholinesterase level reaches $25 \%$ of the pre-exposure value. A decrease of $60 \%$ in RBC AChE level warrants removal from the source of exposure (Blum \& Manzo, 1985).

The relationship between brain cholinesterase inhibition and carbamates toxicity has also been studied. In another series of experiments, the relationship between the brain and plasma cholinesterase activities and the degree of symptoms was studied during the infusion of propoxur into the jugular vein of rats (Plestina, unpublished data). Different rates of infusion, ranging from 0.04 to 0.80 i.v.-LD50/hour, were used. At given time intervals, the animals were sacrificed and their brain and plasma ChE levels were determined spectrophotometrically (Ellman, Courtney et al., 1961) and the analytical procedure was completed within $12 \mathrm{~min}$ after the animals had been decapitated. Three main symptoms (tremor, muscle fasciculations, and salivation) were regularly recorded and were arbitrarily classified according to 5 degrees of intensity. These results show good correlation 
between the activities of the two enzymes and good agreement between the degree of enzyme depression and the intensity of symptoms, the onset of symptoms being recorded only after the brain ChE activity dropped to about $50 \%$ of the normal value. It may be noted that, during the second hour of infusion, a steady state was reached regarding enzyme inhibition and symptom severity (Vandekar, Plestina et al., 1971).

Signs and symptoms of aldicarb intoxication are typically cholinergic and may be ameliorated by the administration of atropine sulphate. Because AChE is present in substantial excess at cholinergic synapses, $60 \%$ to $90 \%$ of the enzyme must be inhibited before the onset of cholinergic dysfunction (35). Symptoms of AChE inhibition and subsequent accumulation of $\mathrm{ACh}$ in nervous tissue and effector organs mimic the muscarinic, nicotinic, and CNS actions of ACh and may be categorised as follows (Blum \& Manzo, 1985):

1. Muscarinic Signs. The stimulation of muscarinic receptors (found primarily in the smooth muscle, the heart, and exocrine glands) results in the following symptoms:
a. tightness in the chest and wheezing due to bronchoconstriction;
b. increased bronchial secretions, salivation, lacrimation, and sweating;
c. increased gastrointestinal tone, with consequent development of nausea, vomiting, abdominal cramps, diarrhea, and involuntary defecation;
d. frequent contraction of the smooth muscle of the bladder, resulting in involuntary urination;
e. bradycardia that can progress to heart blockage;
f. constriction of the pupils.

2. Nicotinic Signs. The accumulation of Ach at the endings of motor nerves to skeletal muscle and autonomic ganglia results in the following symptoms (Blum \& Manzo, 1985):

a. Muscular effects, including easy fatigability and mild weakness, followed by involuntary twitching and cramps. Weakness affects the muscles involved in respiration and contributes to dyspnea, hypoxemia, and cyanosis.

b. Nicotinic actions at autonomic ganglia may, in severe intoxication, mask some of the muscarinic effects. Thus, tachycardia caused by stimulation of sympathetic ganglia may override the usual bradycardia due to muscarinic action on the heart. Elevation of blood pressure and hyperglycemia also reflect nicotinic action at sympathetic ganglia.

Without going into a lengthy discussion of the morphology and function of the mammalian neuromuscular system, the transmission of electrical impulses between nerves and at myoneural junctions generally occurs through the release of chemical transmitters that bind with specific receptors on the postsynaptic terminal or motor end plate, respectively. As the chemical transmitter, $\mathrm{ACh}$ in certain nerve synapses and at neuromuscular junctions binds to the receptor sites; an esterase (AChE) rapidly hydrolyses the ACh into acetyl and choline fractions so that the stimulated nerves or muscles are not continually excited. Essentially, aldicarb and other cholinesterase inhibitors in some way prevent the breakdown of ACh and the subsequent return to a more normal or resting state for the nerve and/or muscle cells (Risher, Mink et al., 1987).

\subsection{Studies of carbamates toxicity in volunteers}

In order to evaluate the toxicity of carbamates in humans, a 42-year-old male volunteer (90 $\mathrm{kg}$ body weight) ingested $1.5 \mathrm{mg}$ of propoxur per $\mathrm{kg}$ of body weight about 2 hours after his 
usual "continental" breakfast. The lowest erythrocyte cholinesterase level $(27.0 \% \mathrm{Y}$ of normal) was observed 15 min after ingestion. No signs were observed at that time, but moderate discomfort, described as "pressure in the head", was present. Blurred vision and nausea developed 3 min later. Twenty minutes after ingestion, the subject was pale and his face was sweating; his pulse rate was 140/min (before ingestion it was $76 / \mathrm{min}$ ) and his blood pressure was $175 / 95 \mathrm{~mm} \mathrm{Hg}$ (before ingestion it was 135/90 $\mathrm{mm} \mathrm{Hg}$ ). Within the next $10 \mathrm{~min}$, pronounced nausea, with repeated vomiting and profuse sweating, developed. These symptoms lasted, with no change in intensity, from about the 30th minute until about the 45th minute, and during this period, erythrocyte cholinesterase activity recovered from a level of $50.4 \%$ to one of $55.5 \%$ of its normal value. One hour after ingestion, the subject was feeling better and his sweating was less pronounced, but he still felt nauseated and tired. His pulse and blood pressure were found to be normal $10 \mathrm{~min}$ later, and $2 \mathrm{hr}$ after ingestion, he was feeling well and he had a complete lunch and dinner without discomfort. The rapid disappearance of symptoms was consistent with the further rapid recovery of erythrocyte cholinesterase activity (Vandekar, Plestina et al., 1971).

Studies examining the acute effects of aldicarb administered orally to human volunteers show the same pattern of rapid acetylcholinesterase inhibition and rapid recovery seen in experimental animal models (NN Hamada, unpublished data). In human subjects, following two preliminary analyses of blood acetylcholinesterase activity, groups consisting of four adult male volunteers each were given aqueous solutions of aldicarb at acute oral doses of $0.025,0.05$, or $0.1 \mathrm{mg} / \mathrm{kg}$. In a similar trial, two subjects were given doses of 0.05 or 0.26 $\mathrm{mg} / \mathrm{kg}$ (Baron \& Merriam, 1988; WHO, 1991; FAO/WHO, 1993). In both trials, individuals were monitored prior to aldicarb exposure and served as their own controls. Observation for signs of poisoning and measurements of whole-blood acetylcholinesterase activity was made for $6 \mathrm{hr}$ following treatment (Baron, 1994).

Acute cholinergic signs and symptoms of overexposure were only observed in subjects exposed to a dose of $0.1 \mathrm{mg} / \mathrm{kg}$ or higher. Clinical signs of overexposure were not noted at doses of $0.05 \mathrm{mg} / \mathrm{kg}$ or lower. By $6 \mathrm{hr}$ after administration, acetylcholinesterase activity had returned to normal, and clinical cholinergic signs and symptoms had disappeared without medical treatment. A dose-related depression from pre-trial values of whole blood acetylcholinesterase was observed in all individuals, mostly for 1 to $2 \mathrm{hr}$ after exposure (Baron, 1994).

In an experimental study with human subjects, three groups of four adult males, all in good health, were administered single oral doses of aldicarb (analytical grade, 99.2\% pure) in water solutions corresponding to $0.1,0.05$, or $0.025 \mathrm{mg}$ insecticide/ $\mathrm{kg}$ body weight. Blood cholinesterase levels were monitored both before and after dosing, and the symptoms resulting from the treatment were observed by physicians. Blood samples were collected from all subjects at $18 \mathrm{hr}$ and $1 \mathrm{hr}$ before ingestion of the aldicarb and at 1,2,4, and $6 \mathrm{hr}$ after dosing. A maximum dose of $0.1 \mathrm{mg} / \mathrm{kg}$ body weight was selected based upon the 0.1 $\mathrm{mg} / \mathrm{kg}$ body weight no-effect level determined in the 2-year rat feeding study of Weil and Carpenter, while the other dosages selected for this experiment were one-half and onefourth of the rat NOEL. Subjects receiving the $0.1 \mathrm{mg} / \mathrm{kg}$ dose manifested a variety of cholinergic symptoms including malaise, weakness in the arms and legs, pupils that were contracted and nonreactive to light, epigastric cramping pain, sweating of hands and forehead, air hunger, frequent yawning, salivation, slurred speech, nausea, and vomiting. The aldicarb-induced cholinesterase depression was reported to be rapidly reversible, and 
by $6 \mathrm{hr}$ after administration, all symptoms had disappeared and the subjects reportedly felt normal again (Risher, Mink et al., 1987).

According to the data above, the mean dose of aldicarb responsible for acute intoxication in humans is about $0.1 \mathrm{mg} / \mathrm{kg}$. The only commercial product containing aldicarb in Brazil is Temik15®, which has a declared percentage of $15 \%$ of aldicarb in its composition. Each Temik15® grain has a mean weight around $0.3 \mathrm{mg}$, which gives an aldicarb mean mass of 45 $\mu \mathrm{g}$ per grain. Thus, the minimum number of Temik15® grains necessary to cause an acute intoxication in humans, and possible the human death, is about 140 grains. Our casuistic at Carlos Éboli Criminalistic Institute includes the analysis of foodstuffs used to cause death (homicide or suicide) containing significantly more than 140 grains of Temik15®.

\section{Legal regulation}

Several countries use the legal regulation of pesticides trading and utilization in order to control and prevent the acute deaths associated with the most toxic compounds described above. In this section we will discuss the effects of the legal regulation of pesticides in some countries and the perspectives for the future application of pesticides in agriculture. We will also explore the current situation of pesticides use in Brazil and the impacts of the legal regulation of these compounds in our country.

Eddleston et al. (2002) discussed four different avenues with potential for reducing the use and availability of pesticides important for acute poisonings: voluntary guidelines, safe-use initiatives, and international policy instruments; changes in farming practice, namely integrated pest management (IPM) and plant biotechnology; direct restrictions of pesticide use; and the introduction of a minimum pesticide list (Eddleston, Karalliedde et al., 2002).

In the early 1980s, debate about the effects of uncontrolled pesticide use on health in the developing world grew worldwide. International organisations, national governments, and industry all responded to these concerns with a series of non-binding proposals (Konradsen, van der Hoek et al., 2003).

The major response was the production of the International Code of Conduct on the Distribution and Use of Pesticides in 1985 by the Food and Agriculture Organisation (FAO) of the United Nations (FAO, 2002). In November 2002, FAO adopted a revised Code of Conduct incorporating concerns and experiences generated since the drafting of the previous version. The Code attempts to rationalise the use of pesticides and reduce the health and environmental risks associated with pesticides establishing:

(...) voluntary standards of conduct for all public and private entities engaged in or associated with the distribution and use of pesticides, particularly where there is inadequate or no national legislation to regulate pesticides. (Article 1.1)

In particular, it wished to ensure that the benefits derived from the use of pesticides be achieved without significant adverse effects on people or environment (Article 1.3).

The new version of the Code of Conduct adapts a 'life-cycle' concept to address all stages from product development to the final disposal of containers and products. Manufacturers are requested to supply only pesticides of adequate quality, packaged and labelled as appropriate for each specific market, and to retain an interest in the product as far as the ultimate consumer, keeping track of uses and the occurrence of problems requiring changes in labelling, directions for use, packaging, formulation or product availability. In particular, the Code states that pesticides whose handling and application require the use of personal protective equipment that is uncomfortable, expensive or not readily available should be 
avoided, especially in the case of small-scale users in tropical climates (Article 3.5) (Konradsen, van der Hoek et al., 2003).

The Code further stipulates that highly toxic and hazardous products (such as WHO Classes Ia and $\mathrm{Ib}$ ) may be prohibited for importation, sale and purchase if other control measures or good marketing practices are insufficient to ensure that the product can be handled with acceptable risk to the user (Article 7.5). Many countries do not enforce these standards, and if the Code were to be followed, the use of Class I pesticides would be prohibited in many developing countries. This issue relates especially to occupational exposure because the required safety equipment is expensive and cumbersome in the tropics and almost never worn (Konradsen, van der Hoek et al., 2003).

National governments are called upon in the Code of Conduct to have the overall responsibility to regulate the availability, distribution and use of pesticides in their countries and should ensure the allocation of adequate resources for the mandate (Article 3.1).

In spite of international efforts to support developing countries in achieving the capacity to implement and supervise the Code of Conduct, many developing countries still do not have this necessary oversight capacity (Konradsen, van der Hoek et al., 2003).

In the second global survey finalised in October 1994 to assess the state of implementation of the Code of Conduct, it was concluded that, although progress had been made towards compliance with various provisions of the Code, there is a continuing need by governments for assistance, especially in the Asia and Pacific region. More than half the national agencies responding to the questionnaire indicated a need for technical assistance and increased government support to strengthen their national capacities and infrastructures necessary to effectively operate their pesticide-control schemes (FAO, 1996).

The crucial role of national-government capacity in enforcing the Code was explicitly acknowledged by the then-Director of the FAO in his introduction to the Code in 1985 (FAO, 1990):

In the absence of effective pesticide registration processes and of a governmental infrastructure for controlling the availability of pesticides, some countries importing pesticides must heavily rely on the pesticide industry to promote the safe and proper distribution and use of pesticides. In these circumstances, foreign manufacturers, exporters and importers, (...), must accept a share of the responsibility for safety and efficiency in distribution and use.

Unfortunately, despite increasing support to improve the capacity of national agencies since the mid-1980s, policing of the Code is still so severely hampered by a lack of resources and political will that there is still no effective mechanism to enforce it or publicise violations. Furthermore, the Code of Conduct does not give direct attention to the issue of self-harm with pesticides and therefore fails to provide policy guidelines or assign responsibilities on this complex issue. Also, the revised Code does not directly call for an elimination of the most hazardous pesticides and that adherence to the great majority of the articles in the Code is voluntary will likely reduce its overall effect on the number of deaths from acute poisoning (Konradsen, van der Hoek et al., 2003). Recently, an updated version of this Code was published, reinforcing these concepts (FAO, 2010).

Piola and colleagues recently showed that a national ban on the organophosphate parathion reduced the number of deaths reported to their poison centre in Rosario, Argentina (Piola \& Prada, 1999; Piola, Prada et al., 2001). Between 1977-1985 and 1990-1994, 21 lethal pesticidepoisoning cases were reported to the centre, including 15 adult cases of self-poisoning and 4 accidental cases in children, 17 of which were due to parathion. Due to the high number of 
deaths occurring nationally with this pesticide, it was banned throughout Argentina in 1994. The last death from parathion in Rosario was reported in 1995. There was a marked fall in the number of deaths due to poisoning from 16 in the first half of the decade to 4 in the second half of the decade (Piola, Prada et al., 2001).

Parathion was also banned in Jordan in 1981 after studies showed that it was responsible for $>90 \%$ of deaths from pesticides in the country. The total number of poisoning deaths undergoing autopsy in Amman fell from 58 in 1978 and 49 in 1980 to 28 in 1982 and 10 in 1984 (Konradsen, van der Hoek et al., 2003).

Paraquat was introduced to Samoa in 1974. Soon after, public-health officials noticed a growing epidemic of self-poisoning. The total suicide rate increased from 10/100,000 in 1974 to $28 / 100,000$ in 1978 to $50 / 100,000$ in 1982 . Because of this epidemic, a community-based campaign was set up to reduce its use for self-harm. At the same time, however, imports fell temporarily due to financial problems. The suicide rate fell rapidly, mirroring the fall in imports, to 15/100,000 within 2 years. Interestingly, the suicide rate between 1984 and 1988, although much reduced at $15-20 / 100,000$, is still more than $80 \%$ due to paraquat and has continued to rise. Suicide with this pesticide had become the method of choice. The pesticide was never banned and remains the cause of around 80\% of all self-harm deaths (Zinn, 1995). Banning paraquat is still the subject of active debate in Samoa today (Konradsen, van der Hoek et al., 2003).

Since the late 1980s, the Sri Lankan government took an active role in determining which pesticides can be used in the country. By the mid-1990s, all Class I pesticides were banned in Sri Lanka. As a result, the number of deaths due to metamidaphos and other Class I organophosphorus fell dramatically, as documented for one district hospital. Unfortunately, another highly toxic (although Class II) compound, the organochlorine endosulfan, then replaced the Class I organophosphorus in agricultural practice. The number of selfpoisoning deaths rose as endosulfan became more popular. Endosulfan was therefore banned in 1998 and deaths fell from 50 to 3 in the same district hospital over the next 3 years. No single compound has since taken its place, but there is currently an increase in the importance of WHO Class II organophosphorus, such as dimethoate and fenthion. Sri Lanka is attempting to shift to less toxic pesticides in the hope that this shift will reduce the number of deaths from deliberate self-poisoning. Thus far, these attempts have been complicated by the replacement pesticides also being sufficiently toxic to cause deaths from self-poisoning. Compared to the early 1990s, there has been little overall effect from switching from one form to another. Future attempts to ban pesticides must carefully predict the likely consequences of switching to another pesticide in agricultural and selfharming practice (Roberts, Karunarathna et al., 2003).

An increased use of pesticides in the Philippines during the 1970 s coincided with a $27 \%$ increase in mortality from non-traumatic causes among economically active men. The incidence in men between the age of 15 and 34 of stroke-a condition rare in this age group but that can be confused with some types of acute pesticide poisoning-also rose during this period but then fell by more than $60 \%$ in the two years following a ban on endrin (Loevinsohn, 1987).

A recent Chinese study concluded that a major component of preventive efforts to reduce acute poisoning in rural areas will be restricting the availability of pesticides. The authors indicate that the availability of potent pesticides in the homes of most residents makes this type of poisoning the preferred method of self-harm (Phillips, Li et al., 2002). This study also supports the idea that not all people who die following acts of self-harm actually wish to die 
(Eddleston, 2000). In a district in Sri Lanka, peaks of fatal self-harm poisoning coincided with ploughing seasons. This trend was not because people were more determined in their self-harm attempts in this season but because it was the time when farmers use paraquat (Hettiarachchi \& Kodithuwakku, 1989). Furthermore, the often impulsive behaviour linked with the ingestion of pesticides and the influence of alcohol during the events makes it important to restrict pesticide availability in homes (Konradsen, van der Hoek et al., 2003).

Overall, these studies suggest that limiting the availability of toxic pesticides will reduce the number of deaths from poisoning and the number of deaths from self-harm. A similar reduction in self-harm deaths has occurred in the UK, Japan, Australia and India following the replacement of barbiturates with benzodiazepines as the most common sedative prescription (Singh, Singhi et al., 1997). Restrictions on availability are currently being adopted by the Ministers of Health of eight Central American and Caribbean countries. These countries have agreed to ban the 12 most problematic pesticides in their region together with a list of 115 pesticides that are restricted in at least one of these countries. The organizers of this approach - the PlagSalud initiative-hope to reduce pesticide poisoning in Central America by $50 \%$ by restricting the most toxic pesticides (Wesseling, Aragon et al., 2001). No results are yet available.

\subsection{Legal regulation In Brazil}

In 2008, Brazil reached the alarming position of the greatest pesticide end user in the world. The National Union of Industries for Agricultural Defensive Products (Sindag, acronym from Portuguese) survey showed that pesticides sales totaled $\$ 7.125$ billion USD, when the country with the second-highest index, the United States, had \$6.6 billion USD in pesticide sales. It is important to highlight the marked increment in Brazilian rural production and export rate and, consequently, the use of agricultural products. Brazil is also the third largest exporting country in the world, losing only to United States and to the European Union, but Brazil was in the sixth place in 2000 . The agricultural-exporting mean rate between the years of 2000 and 2008 has grown by 18\% compared to 10\% for the European Union and 8\% for the United States (Rebelo, Vasconcelos et al., 2010).

There are currently about 600 active compounds used in the formulation of pesticides, legally registered all over the world for use as agricultural chemical defence. Of these compounds, about 350 are part of the composition of $98 \%$ of the most-used pesticides and $80 \%$ are commonly used in the agriculture of Latin American countries, such as Brazil.

The top ten most-used pesticides in Brazil are responsible for $76,45 \%$ of all commercialised pesticides. These compounds are as follows (in decreasing order): glyphosate and salts, cypermethrin, mineral oil, vegetal oil, sulphur, 2,4-dichlorophenoxyacetic acid, atrazine, metamidophos, acephate and carbendanzim. In a class scale, organochlorines are the mostused compounds, followed by organophosphorus, carbamates, and pyrethroids (Rebelo, Vasconcelos et al., 2010).

In Brazil, the 1989 Pesticide Law regulates the research, experimentation, production, packing, labeling, transport, storage, commercialization, final destination of packing, register, classification, control and supervision of pesticides and related compounds. Despite the constant updates of the monographs of pesticides compounds, several substances banned in the European Union and in United States are still used in Brazilian agriculture. Metamidophos, for example, will be totally prohibited in Brazilian farms from June 2012, according to Sanitary National Agency (ANVISA, acronym in Portuguese). 
Aldicarb, used as insecticide, acaricide or nematicide in potato, coffee, sugar cane, and citrus cultures, is considered extremely toxic. This substance is produced in only one industry in the United States. The use of this substance as a pesticide is prohibited in more than 60 countries, including members of the European Union. In the state of California in the United States, close to 2000 people showed intoxication symptoms after eating contaminated fruit in 1985. Despite this great toxic potential, the deadline for use in the USA is August 2018, according to the factory producer. In Latin America, this substance is legally used in Brazil, Chile, Argentina, Peru and Colombia, among other countries. This pesticide is also used in Australia and in South Africa; in the latter, there are several problems related to misuse, as in Brazil. The formulated aldicarb product to Brazil is special and includes the addition of a distressingly agent, denatonuim benzoate, to avoid accidental ingestion by humans and/or animals. This product arrives in Brazil, and a sole importer in São Paulo State receives and distributes it to a few allowed resales in three states, only to registered and certified farmers. Aldicarb is one of the five most-used pesticides in the state of Bahia.

Several banned pesticides in European Union and in United States are still commonly used in Brazilian crops. The regulatory agencies are working very slow in the law revision of the real necessity of using these pesticides. In 2008, 14 substances were sent to be evaluated; from this group, eight (methyl parathion, lacotophen, phorate, carbofuran, abamectin, tyran, paraquat and glyphosate) are still waiting for government decision (February of 2011). Cyhexatin, used in citrus, has been banned since 2011. In a revision published in 2010, trichlorfon was banned in Brazil. In addition, the commercialisation of all the formulated products with endosulfan will be cancelled from 2013 by manufacturer solicitation, and the use and application of phosmet products were reassessed. A 2011 publication has mandated the banning of methamidophos starting in June 2012.

Regarding aldicarb, the deadline of its use is 2018, according to information from the manufacturer. In Brazil, in relation to intoxications, the main problem is the irregular commercialisation of aldicarb-based products in small packaging containing about five grams of the product for use as a rodenticide. Nevertheless, this substance has one common fault as a rodenticide; it produces symptoms very rapidly. Rodent behaviour is such that an individual encountering a new food for the first time will normally test feed and may not take a substantial quantity for many hours or even days (Hadler \& Buckle, 1992). If the bait causes distressing symptoms during the test-feeding period, the rodent is intelligent enough to recognise cause and effect and becomes "poison shy" or 'bait shy.' However, it is very common to find the irregular street trade of this product in big urban centres, far from agricultural regions. To the facility of obtaining this product in small doses, it is usual the association of aldicarb in crime scenes, generally in the typical grains of the commercial product and in the package used in irregular trade.

Brazilian legislation imposes that subdivision and packaging of pesticides are restricted to the manufacturer or to the handler, supervised by the producer, and used in conditions and places pre-authorised by the government. In addition, pesticides can only be sold directly to the final user and with the legally licensed professional prescription submission. This irregular trade also disrespects the Environmental Law that considers the production, processing, packaging, import, export, trade, gift, transport, maintenance, keeping, storing or use of substances that are dangerous or harmful to human health or the environment to be a crime, in disagreement with specific legislation. 


\section{Forensic analysis of pesticides}

As forensic laboratories work for the Justice, their responsibility is very peculiar. Analysis certifies the eventual correlation between illness and toxicity, and in medico-legal cases, the presence of a poison furnishes the first and foremost evidence. Whichever is the cause of poisoning (therapeutic, industrial or criminal), even if damage is not voluntary, common law imposes at least compensation for the ill effects that follow intoxication. This aspect, which is of great importance, shows the permanence of the relationship between toxicology and forensic medicine, which requires an exceptional security of the methods used in the laboratory and extreme prudence in statement and interpretation of results.

The wide variety of matrices and pesticides associated with homicides and suicides, as described above, requires the development of detection and quantification techniques with adequate precision and accuracy of pesticides residues in different matrices, such as water, soil, foodstuffs and biological matrices.

The main pesticides associated with intoxications and the instrumental methods used in forensic analysis of these compounds in different matrices are organochlorines, organophosphorus, and carbamates.

Organochlorine pesticides are composed by carbon and chlorine atoms in several isomers conformations from hexachlorocyclohexane and from cyclodienes. The main representative substances of this group are cyclohexanes (BHC, DDT, lindane, pentachlorophenol) and cyclodienes (aldrin, endrin, endosulphan). The organophosphorus have, with no exception, a central pentavalent phosphorus atom linked to an oxygen or sulphur atom by a double covalent linkage and can be represented by the compounds Malathion, Parathion, and others. Finally, the carbamate pesticides are compounds derivated from carbamic acid, and their main substances analysed in toxicological laboratories are aldicarb, carbofuran and carbaril (Figure 3).

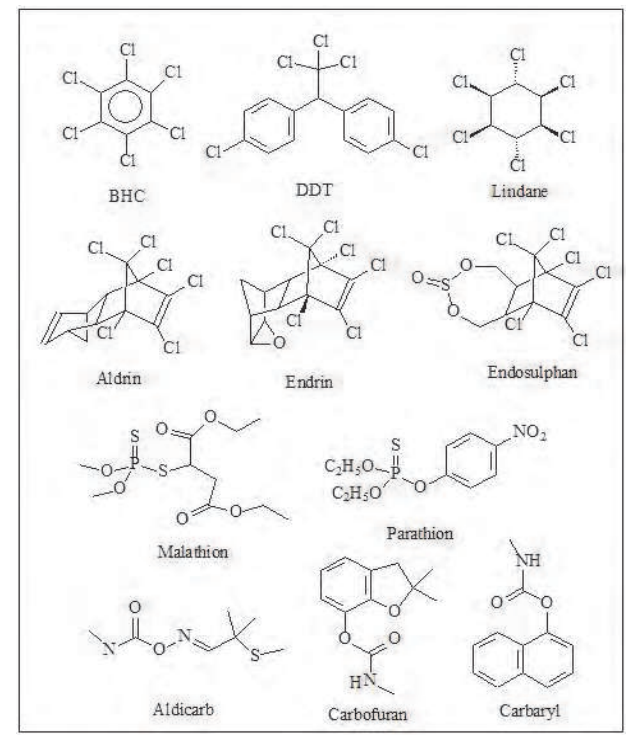

Fig. 3. Chemical structures of some pesticides 
In the last few years, several studies have been published based on the development of more precise, cheaper and faster analytical procedures. Analytical chemistry has witness a significant improvement with the establishment of new methodologies by the use of more sensible instrumental techniques that use small quantities of samples, such as mass spectrometry (MS), Fourier Transform Infrared Spectroscopy (FTIR) and Ultraviolet-Visible Spectrometry (UV-Vis) and Raman Spectrometry (RAMAN).

Pesticide analysis in different matrices is traditionally accomplished using chromatographic techniques and liquid and gas chromatography in particular. These techniques are used because of their capacities to separate the compounds present in a sample and to permit the identification and quantification of these compounds using specific detector systems. The identification and quantification of pesticides can be accomplished by coupling the detectors, such as electron capture (Suchan, 2004), fluorescence (Nedelkoska, 2004), UV-VIS (Nedelkoska, 2004), flame ionisation (Engelmann, 2003) and MS, with the chromatographic systems.

For gas-chromatography (GC) separation, a great variety of stationary phases have been used in capillary columns. Most research groups have only used one column for the same class of pesticides. However, some authors have reported the use of two columns with different polarities and different geometric parameters under the same or different chromatographic conditions to confirm the peak identification. Different columns have also been used to compare mass spectrometry detectors to classical detectors for analysing residues from the same class of pesticides, even more so when compounds from different pesticide classes were analysed in one run in gas chromatography coupled to mass spectrometry (CG-MS). GC is combined with different types of detection methods, mainly depending on the class of pesticides to be detected. Electron-capture detection (ECD) is often employed for organochlorine and pyrethroid analyses. Electrolytic-conductivity detection after GC separation has also been proposed for the detection of several pesticides residues, including organochlorines, pyrethroids, triazines and carbamates. Both flame photometric detection (FPD) with a phosphorus filter and nitrogen-phosphorus detection (NPD) have been used for organophosphorus detection. Besides these conventional elementspecific detection methods, GC use with mass spectrometric detectors, including singlequadrupole, ion-trap, and triple-quadrupole mass spectrometers, has been adapted to the analysis of pesticides. The use of MS has the advantages over conventional element-specific detectors of being able to determine pesticides from different classes (organochlorines, organophosphorus, pyrethroids, triazines and carbamates) in the same acquisition run (LeDoux, 2011).

Parveen et al. monitored pesticide residues belonging to different pesticide classes, such as organochlorines, organophosphorus, pyrethroids and carbamates, in 206 vegetables samples from Karachi, Pakistan using HPLC and GC-FID (Parveen, Khuhro et al., 2005).

Pesticide residues of organochlorines, organophosphorus, pyrethroids and carbamates groups in fruits and vegetables were monitored in Sao Paulo City, Brazil by Gebara et al. (Gebara, Ciscato et al., 2005). A total of 2223 samples comprising 700 vegetables and 1523 fruits collected from general stores and wholesale shops were analysed for 100 pesticide residues of insecticides and fungicides with GC equipped with different detectors (ECD, NPD, FPD).

Fresh foodstuffs from El Ejido, Almeria, Spain were collected from September 2001 to July 2002 to monitor 81 multiclass pesticides (organophosphorus, organochlorines and pyrimidine) in approximately 4000 vegetable samples by Arrebola et al. (Arrebola, 2003). 
The analysis was conducted through single injection using gas-chromatography chemical ionisation and electron ionisation tandem mass spectrometry (GC-MS-MS).The vegetable samples were extracted in dichloromethane for multi-pesticide residues of dichlorvos, methamidophos, mevinphos, acephate, omethoate, lindane, diazinon, disulfoto, parathionmethyl, chlorpyrifos, malthion, fenthion, dicofol, ethion, endosulfan-I, II, permethrin, cyfluthrin and deltamethrin and were analysed with GC-MS-MS.

Liquid chromatography has been used for the analysis of polar and/or non-volatile and/or thermally labile pesticides for which GC conditions were not suitable, mainly carbamates and triazines. Various stationary phases have been tried for the separation of pesticides (Pacáková, 1996), but reverse phase is generally preferred (LeDoux, 2011). Liquid chromatography has also been combined with conventional detectors, such as fluorescence or UV detectors, to identify and quantify pesticides. The first has been used for carbamates analyses and the second for triazines analyses. Liquid chromatography coupled with a diode-array detector (LC-DAD) has been used in triazine and carbamate analyses (Baranowska, 2005; Baranowska, 2006). Recently, liquid chromatography has been coupled with different kinds of mass spectrometric detectors, including single-quadrupole, ion-trap, tandem-MS, and time-of-flight MS (TOF-MS), to determine pesticides in aqueous and solid environmental samples and in foods of vegetable origin (Pico, Blasco et al., 2004; Hercegová, 2007; LeDoux, 2011).

Recently, the number of compounds that are only amenable to liquid-chromatographic techniques has increased in relation to those amenable to the previously widely used gaschromatographic techniques. For this reason, liquid-chromatography mass spectrometry (LC-MS/MS) detection systems are increasingly commonly used (Sannino, 2004; Soler, 2004; Liu, 2005; Soler, 2005; Soler, 2005; Soler, 2007; Kmellár, 2008). B. Kmellar et al. developed a sensitive multi-residue pesticide method for the determination of 160 multi-class pesticides in different kinds of vegetables using an LC-MS/MS system (Kmellár, 2008).

Liu et al. determined carbamates and organophosphorus in 25 samples, including vegetables and fruits, using LC-MS. All samples were collected from local markets and supermarkets in China (Liu, 2005).

Special care must be taken when using the techniques mentioned above that the preparation, extraction and clean-up of the samples are performed well, especially the most complex steps, to reduce the matrix effects. Even with the advent of advanced hyphenated techniques based on mass spectrometry, some complex fatty matrices usually require extensive sample extraction and purification (Gilbert-López, 2009). There are diverse methods of extraction described in the literature, such as solid-liquid extraction, liquidliquid extraction, supercritical-fluid extraction, Soxhlet extraction and microwave-assisted extraction. The best method will depend on the sample matrix to be analysed. Current methods involve the use of one or more of the techniques for the sample-extraction steps. Several solid-liquid extraction and liquid-liquid extraction protocols have been standardised for extracting 23 organochlorines and 22 organophosphorus residues from the fatty foods of animal origin (milk and milk products, meat and meat products, fish and seafood, eggs) (European_Committee_of_Standardization, 1996).

In GC-MS analysis of carbamate, organophosphorus and organochlorine pesticides, the use of solvent extraction is recommended, such as chloroform or dichloromethane. In HPLC analysis, the recommended solvents are acetonitrile or methanol, and for thin layer chromatography, acetone (Passagli, 2009). 
Moreover, co-extracted matrix constituents, especially lipids, can interfere with targetcompound identification. Several approaches have been attempted to eliminate coextraction interference from extracts, including freezing centrifugation, liquid-liquid partitioning, gel-permeation chromatography (GPC), solid-phase extraction (SPE), solidphase micro-extraction (SPME) matrix solid-phase dispersion (MSPD), etc. Out of all of these techniques, the most commonly applied approach for pesticides extraction in fatty vegetable matrices so far is liquid partitioning with organic solvents followed by a clean-up with SPE or GPC (Gilbert-López, 2009).

Cases involving acute fatalities due to ingestion of organophosphorus pesticides, such as chlorpyrifos, diazinon, malathion and parathion, are presented by Mee-Jung Park et al. In this work, SPE and GC-MS were used for the analysis of organophosphorus in post-mortem blood (Park 2009).

Traditional chromatographic methods are effective for the environmental analysis of pesticides but have limitations and require adequate monitoring. Enzymatic methods have been used for many years as an alternative method of the detection of pesticides. The main enzymes used are acetylcholinesterase, butyrylcholinesterase, alkaline phosphatase, organophosphorus hydrolase and tyrosinase. The enzymatic methods are based on the proportional activation or inhibition of the enzyme with the concentration of the pesticide. Research on enzymatic methods of detection and some of the problems and challenges associated with these methods are extensively discussed in a review written by Van Dyk et al. These methods can serve as a tool for screening large samples and can be followed up with the more traditional chromatographic methods of analysis (Dyk, 2011).

Our group in Brazil developed a simple and low-cost methodology based on the inhibition of a stable preparation of the enzyme acetylcholinesterase obtained from rat brain specially adapted for forensic purposes. The method proved to be precise and accurate, detecting as little as $40 \mu \mathrm{g} / \mathrm{kg}$ of the pesticide aldicarb in meat samples (Sabino, Torraca et al., 2010). The technique comprises an initial extraction step with the solvent methylene chloride followed by a colourimetric acetylcholinesterase assay. This method is rapid and cheap, demanding only basic laboratory equipment and glassware. Although the method was validated for use with meats samples, it can be easily adapted for other matrices. Taking into account that all other carbamates are also potent enzyme inhibitors but that aldicarb is the contaminant most frequently found in Brazil, the results of contaminated forensic samples were expressed in aldicarb equivalents. This method could also be adapted to detect thionophosphate insecticides (Cunha Bastos V, 1991; de Lima, Bastos Neto Jda et al., 1996; Sabino, Torraca et al., 2010).

\subsection{Forensic analysis of pesticides in Brazil}

In our routine at the Chemistry Division of Carlos Éboli Rio de Janeiro Criminalistic Institute (SPQ-ICCE-RJ, acronym in Portuguese), we seldom receive food contaminated with pesticides, especially Temik15®, used in homicide and suicide intoxications. In such cases, the use of a TLC technique is not always capable of revealing the presence of aldicarb due to the lipids presents in food that hinder the chromatographic separation of the compounds. In these cases, the use of the enzymatic methodology described above was applied and showed good results (data not published).

Vibrational spectrometry provides useful, well-established analytical techniques for quantitative determinations of major and minor components from solid, liquid and gaseous 
samples. Applications of Fourier-transform infrared (FTIR) and FT-Raman spectrometry can be found in a variety of fields, from pharmaceuticals to paint solvents, and the references found in the literature related to different procedures based on the use of both techniques have grown dramatically in recent years. This effect is probably due to the improvements in FT-based equipment and the decreasing acquisition and maintenance cost, together with the advances in automation that enhance data acquisition. Armenta et al. showed the applicability of vibrational spectrometry, basically FTIR and FT-Raman, for the analysis of pesticides in agrochemical formulations. The main advantage that FT-Raman presents over FTIR spectrometry is the very weak Raman spectra of glass, water and plastic packaging, which allow direct analysis of samples inside glass bottles or plastic bags without opening the package, thus minimising the risk of contamination. In this article, it is clearly shown that these techniques enable fast, non-destructive, precise and accurate measurements, and thus vibrational spectrometry is a promising tool for analysis in the agrochemical-industry samples (Armenta, 2005).

In Brazil, thin-layer chromatography (TLC) is still a common technique used in pesticide identification in forensic toxicological and chemistry laboratories. It is widely used in laboratories throughout the world for food analysis and quality control. Numerous applications of TLC have been reported in the areas of food-composition intentional additives, adulterants, contaminants, and decomposition involving determinations of compound classes. This old technique consists of the separation of compounds in a mixture by differential migration through an adsorbent layer withheld in a plane surface plate. It is also routinely used in many laboratories in the chemical/pharmaceutical and related industries for both qualitative and semi-quantitative work. It is a simple, fast and economic technique. There is considerable literature describing pesticide analysis by TLC with environmental and food monitoring. Marcos P. work describes the use of this technique in carbamate (aldicarb, carbofuran, carbaryl and propoxur) pesticide identifications by applying a mixture of hexane/ethyl acetate (6:4) (Passagli, 2009).

In Brazilian forensic laboratories, especially outside the big urban centres, there is an enormous lack of instrumental methodologies. In these laboratories, the main technique available to the forensic scientist to determine the presence of a pesticide in a material is TLC. The major disadvantage of TLC is its limited sensitivity when compared to other instrumental techniques (GC-MS and LC-MS).

General reviews of pesticide TLC analysis, including some information on the analysis of foods, crops, and other agricultural samples, have been published (Chen \& Wang, 1996; Torres, Pico et al., 1996; Sherma, 2000). Diverse papers describing the analysis of synthetic pyrethroids and their metabolites using thin-layer chromatography have been reported: cypermethrin in soil and in animals, deltamethrin in animals (Ruzo, Engel et al., 1979), fenpropathrin in water, soil and plants, fenvalerate in plants, permethrin in insects and plants, permethrin and cypermethrin in soil and plants (Chen \& Wang, 1996). Carbofuran and its environmental by-products, hydroxycarbofuran and 3-ketocarbofuran, were analysed using high-performance TLC. Carbaryl, aldicarb, oxamyl, butocarboxim and butoxycarboxim and several other pesticides in drinking water were detected at picogram levels by coupling TLC with an enzymic inhibition test designed for cholinesteraseinhibiting insecticides (Yang, Goldsmith et al., 1996).

Currently, gas chromatography is widespread and extremely valuable in routine analysis in Brazilian forensic laboratories. The ability to couple this technique to mass spectrometry has enhanced its use in drug analysis, pesticide identification in foodstuffs and environmental 
samples, and perfume control quality, among others. There are several works describing pesticide identifications using gas chromatography coupled to mass spectrometry (GC-MS). Marcos P. work uses this technique in the identification of some organophosphorus pesticides (chlorpyriphos, armitraz and diazinon) and carbamate pesticides (aldicarb, carbophuran, carbaryl and propoxur) (Passagli, 2009).

Another important technique used in Brazilian forensic toxicological and chemistry laboratories is high-efficiency liquid chromatography (HPLC). This technique is an imperative tool used in forensic laboratories in Brazil and in other countries around the world. It is very common to see the use of this type of equipment in forensic television programs, such as CSI, CSI Miami, Crossing Jordan, and Law and Order, to obtain criminal evidence. The application of this technique is not limited to forensic chemistry but is also used in biochemistry, environmental sciences, pharmacological chemistry, and toxicology. HPLC uses a liquid mobile phase and a finely divided stationary phase in the chromatography system. The main detectors coupled to HPLC are based in the absorption of ultraviolet or visible radiation. Marcos P. Work uses this technique in carbamate-pesticide (aldicarb, carbophuran, carbaryl and propoxur) and in coumarinic-rodenticide (cumatetralil, bromadiolone, brodifacoum and difethialone) identifications, which are the most common compounds used in suicide attempts (Passagli, 2009). A few toxicological laboratories in Brazil have a mass spectrometer coupled to HPLC equipment, but there is a growing number of laboratories using this association due to its great sensibility and to the preparation facility of aqueous samples compared to GC-MS.

The previously cited techniques could also be used in association with other techniques, such as spectroscopic techniques. Recently, SPQ-ICCE-RJ have acquired FTIR equipments. The infrared absorption technique is able to detect microscope residues without sample damage, a substantial forensic advantage allowing future sample re-analysis. The interaction of infrared light with the substance alters the vibrations of atoms, giving important information that permits the identification of the compound. The FTIR spectrometer can be used in diverse matrices (solids, liquids and pastes) and has a coupled library that can be used in the compounds identifications. The FTIR applications are very diverse and have a huge contribution in several pesticide-identification occurrences.

\subsubsection{Forensic cases in Brazil}

Some suicide and homicide attempts are described next, including photos of materials collected in police occurrences, which were identified as pesticides using the instrumental techniques cited above. The use of the distressingly agent, denatonium benzoate, in the formulation of Temik15 ${ }^{\circledR}$ to avoid accidental ingestion may explain why the number of completed homicides using this product is low.

The use of crossing techniques has permitted the unequivocal identifications of the substances, enhancing the results' reliability. About ten years ago, SPQ-ICCE-RJ only used TLC comparative with standard solutions of the pesticides to identify the presence of a pesticide in a sample. With the introduction of other techniques (FTIR and GC-MS), other compounds that were not previously detected have been identified, increasing the toxicsubstance positive-identification index and the number of cases resolved. Recently, homicide attempts using juice contaminated with cypermethrin and water contaminated with chlorpyrifos were solved using the GC-MS technique. 
The use of FTIR techniques in forensic science in association with other analytical techniques or as a stand-alone method, increases the quality of the results available to assist with the solving of police cases and, consequently, improves justice.

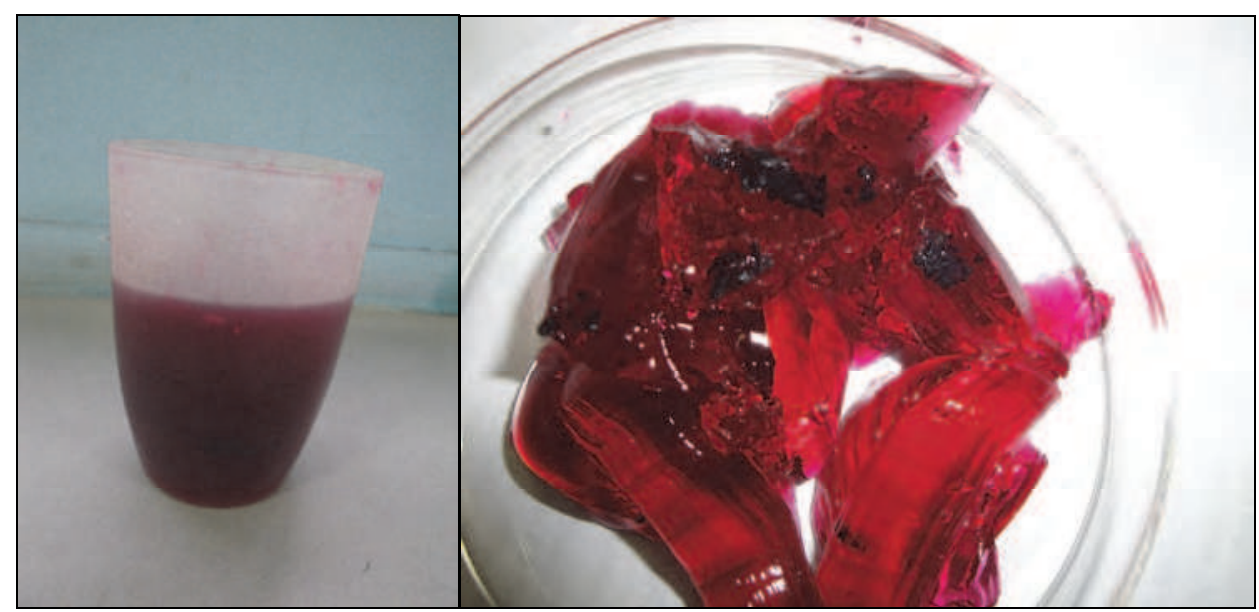

Fig. 4. Homicide attempt. Glass with jelly found in the victim's refrigerator possibly left by his cousin. The grey-coloured grains permeated into the food. The use of TLC, GC-MS, and FTIR instrumental techniques permitted the identification of aldicarb and carbophuran in the grains found in the food.

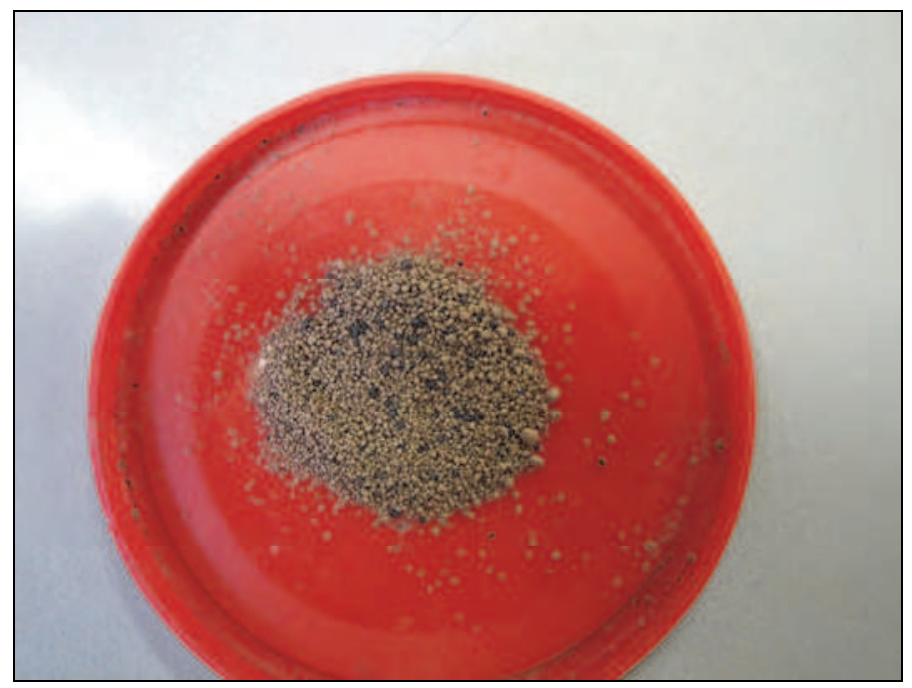

Fig. 5. Homicide attempt against a child possibly accomplished by the stepmother. A tin containing a mixture of chocolate powder and grey-coloured grains. The use of TLC and FTIR instrumental techniques permitted the identification of aldicarb in the grains found in the food. 


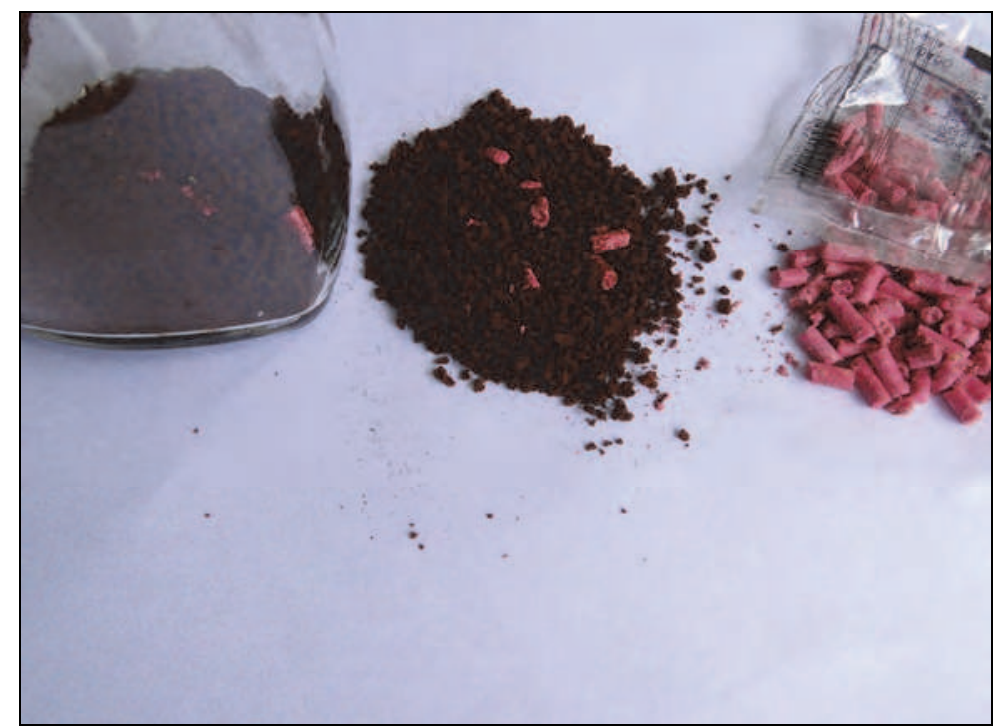

Fig. 6. Homicide Attempt. Mixture of coffee and typical rose grains. The use of TLC permitted the identification of a coumarin compound used in rodenticide formulations.

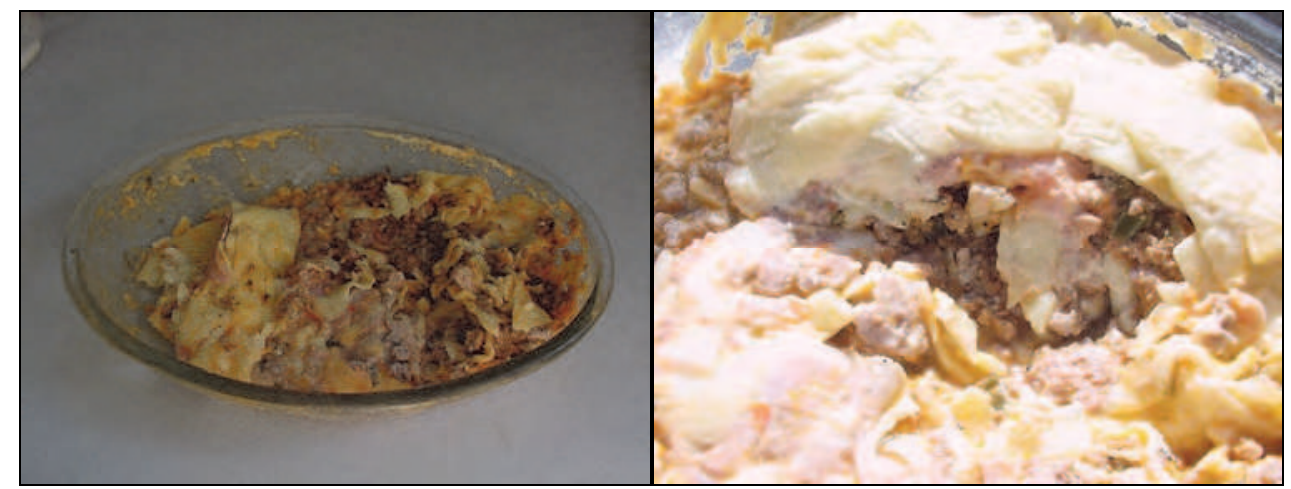

Fig. 7. Suicide. Food (pasta) found next to the corpse. On the surface of the food, greycoloured grains were identified. The use of TLC and FTIR instrumental techniques permitted the identification of aldicarb in the grains found in the food.

\section{Conclusions}

This study has clearly shown that pesticides, specially carbamates, are extensively used in Brazil and other countries for self-poisoning and homicides attempts, and contributes to the population patterns of morbidity and mortality in these developing nations. These results point to the need of a deep investigation of poisonings in these areas and for the implementation of strategies that would minimize the number of cases related to intentional and unintentional pesticide poisoning. 
In our text we have presented several examples where government restriction to the most hazardous pesticides were of great importance in reducing the number of poisoning cases and deaths related. Government actions, such as educational and preventive programs, stronger regulation and a more efficient information system are essential to access and avoid intentional poisoning involving the use of pesticides. Moreover, the adequate control of pesticides trade must be effective to prevent the free access of the population to these toxic compounds.

Action has to be effective at least in the areas of pesticide policy, pesticide information, mental healthcare, clinical management of pesticide intoxication and occupational safety. The role of forensic sciences in this context is crucial to identify the compounds involved in the poisoning and characterize the criminal intent in an homicide attempt, for example. Besides, the results obtained in forensic laboratories could be used to generate a valuable database of the most common used pesticides for poisoning. Such database would help the activities of the regulatory agencies concerning the compounds most used in crimes against life. However, taken into account the complex chemical structures and wide variety of pesticides and matrices used in human poisoning, the Criminalistic Institutes must have adequate and validated techniques and advanced analytical equipments to be able to perform the chemical analysis of these samples.

\section{Acknowledgements}

The authors thank the Rio de Janeiro Police Department and Institute of Criminalistics for providing the data of apprehended samples, and the Brazilian science foundation's FAPERJ for financial assistance.

\section{References}

Abdullat, E. M., Hadidi, M. S., et al. (2006). Agricultural and horticultural pesticides fatal poisoning; the Jordanian experience 1999-2002. J Clin Forensic Med, 13, 6-8, 304-7.

Armenta, S. Q. s., G.; Garrigues,S.; De la Guardia, M. (2005). Mid-infrared and Raman spectrometry for quality control of pesticide formulations. Trends in Analytical Chemistry, 24, 8, 772-81.

Arrebola, F. J., Martínez Vidal, J. L.; Mateu-Sánchez, M.; Álvarez-Castellón, F. J. (2003). Determination of 81 multiclass pesticides in fresh foodstuffs by a single injection analysis using gas chromatography-chemical ionization and electron ionization tandem mass spectrometry Analytica Chimica Acta, 484, 2, 167-180.

Baranowska, I. B., H.; Pacak, E. (2006). Procedures of trophic chain samples preparation for determination of triazines by HPLC and metals by ICP-AES methods Environmental Pollution, 143, 2, 206-211.

Baranowska, I. B., H.; Pyrsz, A. (2005). Distribution of pesticides and heavy metals in trophic chain Chemosphere, 60, 11, 1590-1599.

Baron, R. L. (1994). A carbamate insecticide: a case study of aldicarb. Environ Health Perspect, 102 Suppl 11, 23-7.

Baron, R. L. \& Merriam, T. L. (1988). Toxicology of aldicarb. Rev Environ Contam Toxicol, 105, 1-70.

Berger, L. R. (1988). Suicides and pesticides in Sri Lanka. Am J Public Health, 78, 7, 826-8. 
Blum, K. \& Manzo, L. (1985). Neurotoxicology, Marcel Dekker, Inc., New York.

Casey, P. \& Vale, J. (1994). Deaths froms pesticides poisoning in England and Wales: 19541989. Hum Exp Toxicol., 13, 95-101.

Chen, Z. M. \& Wang, Y. H. (1996). Chromatographic methods for the determination of pyrethrin and pyrethroid pesticide residues in crops, foods and environmental samples. J Chromatogr A, 754, 1-2, 367-95.

Cunha Bastos V, C. B. J., Lima J, Castro Faria MV. (1991). Brain acetylcholinesterase as an in vitro detector of organophosphorus and carbamate insecticides in water. . Water Research, 25, 7, 835-40.

Daisley, H. \& Hutchinson, G. (1998). Paraquat poisoning. Lancet, 352, 9137, 1393-4.

de Lima, J. S., Bastos Neto Jda, D., et al. (1996). Methyl parathion activation by a partially purified rat brain fraction. Toxicol Lett, 87, 1, 53-60.

Dyk, J. S. V. P., B. (2011). Review on the use of enzymes for the detection of organochlorine, organophosphate and carbamate pesticides in the environment. Chemosphere 82, 291-307.

Eddleston, M. (2000). Patterns and problems of deliberate self-poisoning in the developing world. Qjm, 93, 11, 715-31.

Eddleston, M., Karalliedde, L., et al. (2002). Pesticide poisoning in the developing world--a minimum pesticides list. Lancet, 360, 9340, 1163-7.

Eddleston, M. \& Phillips, M. R. (2004). Self poisoning with pesticides. Bmj, 328, 7430, 42-4.

El Cadi, M., Mezzane, A., et al. (2008). Fatal pesticides poisoning in Morocco (2000-2005). Ann Toxicol Anal., 20, 2, 73-77.

Ellman, G. L., Courtney, K. D., et al. (1961). A new and rapid colorimetric determination of acetylcholinesterase activity. Biochem Pharmacol, 7, 88-95.

Engelmann, M. D. H., R.; Henschied, K.; Neal, R.; Cheng, F. (2003). Simultaneous determination of total polychlorinated biphenyl and dichlorodiphenyltrichloroethane (DDT) by dechlorination with $\mathrm{Fe} / \mathrm{Pd}$ and $\mathrm{Mg} / \mathrm{Pd}$ bimetallic particles and flame ionization detection gas chromatography. Microchemical Journal, 74, 19.

European_Committee_of_Standardization (1996). Official Method of analysis EN1528/1-4. Brussels.

FAO. (1990). International Code of Conduct on the Distribution and Use of Pesticides (amended to include Prior Informed Consent in Article 9 as adopted by the 25th Session of the FAO Conference in November 1989). FAO, Rome.

FAO. (1996). Analysis of Government Responses to the Second Questionnaire on the State of Implementation of the International Code of Conduct on the Distribution and Use of Pesticides. FAO, Rome.

FAO. (2002). International Code of Conduct on the Distribution and Use of Pesticides. FAO, Rome.

FAO. (2010). International Code of Conduct on the Distribution and Use of Pesticides. FAO, Rome.

FAO/WHO. (1993). Pesticide residues in food. 1992 Report of the Joint Meeting of the FAO Panel of Experts on Pesticide Residues in Food and the Environment and the WHO 
Expert Group on Pesticide Residues. FAO Plant Production and Protection Paper 116. Rome:Food and Agriculture Organization of the United Nations.

Gebara, A. B., Ciscato, C. H., et al. (2005). Pesticide residues in vegetables and fruits monitored in Sao Paulo city, Brazil, 1994-2001. Bull Environ Contam Toxicol, 75, 1, 163-9.

Gilbert-López, B. G.-R., J.F.; Molina-Díaz, A. (2009). Sample treatment and determination of pesticide residues in fatty vegetable matrices: A review. Talanta, 79, 109-128.

Hadler, M. \& Buckle, A. (1992). forty five years of anticoagulant rodenticides - Past, Present and Future Trends. Proc. 15th Vertebrate Pest Conf., 149-155.

Hercegová, A. D., M.; Matisová, E. (2007). Sample preparation methods in the analysis of pesticide residues in baby food with subsequent chromatographic determination. Journal of Chromatography A, 1153, 1-2, 54-73.

Hettiarachchi, J. \& Kodithuwakku, G. C. (1989). Pattern of poisoning in rural Sri Lanka. Int J Epidemiol, 18, 2, 418-22.

Joseph, A., Abraham, S., et al. (2003). Evaluation of suicide rates in rural India using verbal autopsies, 1994-9. Bmj, 326, 7399, 1121-2.

Kasilo, O. J., Hobane, T., et al. (1991). Organophosphate poisoning in urban zimbabwe. J Appl Toxicol, 11, 4, 269-72.

Kmellár, B. F., P.; Pareja,L.; Ferrer, C.; Martínez-Uroz, M.A.; Valverde, A.; Fernandez-Alba, A.R. (2008). Validation and uncertainty study of a comprehensive list of 160 pesticide residues in multi-class vegetables by liquid chromatography-tandem mass spectrometry. Journal of Chromatography A, 1215, 37-50.

Konradsen, F., van der Hoek, W., et al. (2003). Reducing acute poisoning in developing countries--options for restricting the availability of pesticides. Toxicology, 192, 2-3, 249-61.

LeDoux, M. (2011). Analytical methods applied to the determination of pesticide residues in foods of animal origin. A review of the past two decades. Journal of Chromatography A, 1218, 1021-1036.

Liu, M. H., Y.; Song,Y. , Lin, J.M. (2005). Simultaneous determination of carbamate and organophosphorus pesticides in fruits and vegetables by liquid chromatographymass spectrometry Journal of Chromatography A, 1097, 1-2, 183-187.

Loevinsohn, M. (1987). Insecticide use and increased mortality in rural central Luzon, Philippines. Lancet, 13, 1359-1362.

Manuel, C., Gunnell, D. J., et al. (2008). Self-poisoning in rural Sri Lanka: small-area variations in incidence. BMC Public Health, 8, 26.

Meyer, T., Resende, I., et al. (2007). Incidence of suicides and rural workers' use of pesticides in Luz. Rev. bras. Saúde ocup., 32, 116, 24-30.

Nalin, D. R. (1973). Epidemic of suicide by malathion poisoning in Guyana. Report of 264 cases. Trop Geogr Med, 25, 1, 8-14.

Nedelkoska, T. V. L., G. K. C.;. (2004). High-performance liquid chromatographic determination of glyphosate in water and plant material after pre-column derivatisation with 9-fluorenylmethyl chloroformate. Analytica Chimica Acta, 511, 145. 
Nesime, Y., Lokman, B., et al. (2004). Acute pesticide poisoning related deaths in Turkey. Vet Hum Toxicol, 46, 6, 342-4.

Pacáková, V. S., K.; Jiskra, J. (1996). High-performance separations in the determination of triazine herbicides and their residues. Journal of Chromatography A, 754, 1-2, 17-31.

Park , M. J. I., S.W; Lee, S.K.;Choi, W.K.; Park, Y.S.; Chung, H.S. (2009). Postmortem blood concentrations of organophosphorus pesticides. Forensic Science International, 184, 28-31.

Parveen, Z., Khuhro, M. I., et al. (2005). Monitoring of pesticide residues in vegetables (2000-2003) in Karachi, Pakistan. Bull Environ Contam Toxicol, 74, 1, 170-6.

Passagli, M. (2009). Toxicologia Forense Teoria e Prática, Millennium, Campinas.

Phillips, M. R., Li, X., et al. (2002). Suicide rates in China, 1995-99. Lancet, 359, 9309, 835-40.

Pico, Y., Blasco, C., et al. (2004). Environmental and food applications of LC-tandem mass spectrometry in pesticide-residue analysis: an overview. Mass Spectrom Rev, 23, 1, 45-85.

Piola, J. \& Prada, D. (1999). Influencia de medidas regulatorias en la morbilidad y mortalidad por talio y parathion en Rosario, Argentina. Acta Toxicol. Argent., 7, 4143.

Piola, J., Prada, D., et al. (2001). Intoxicaciones con evolucion letal atendidas en Rosario, 1990-1999. Rev. Med. Rosario, 67, 19-24.

Rebelo, R., Vasconcelos, R., et al. (2010). Instituto Brasileiro do Meio Ambiente e dos Recursos Naturais Renováveis (IBAMA). Produtos agrotóxicos e afins comercializados em 2009 no Brasil: uma abordagem ambiental, In

http://www.ibama.gov.br/qualidade-ambiental/wpcontent/files/Produtos_Agrotoxicos_Comercializados_Brasil_2009.pdf,

Recena, M., Pires, D., et al. (2006). Acute poisoning with pesticides in the state of Mato Grosso do Sul, Brazil. Science of the Total Environment, 357, 88-95.

Risher, J. F., Mink, F. L., et al. (1987). The toxicologic effects of the carbamate insecticide aldicarb in mammals: a review. Environ Health Perspect, 72, 267-81.

Roberts, D. M., Karunarathna, A., et al. (2003). Influence of pesticide regulation on acute poisoning deaths in Sri Lanka. Bull World Health Organ, 81, 11, 789-98.

Ruzo, L. O., Engel, J. L., et al. (1979). Decamethrin metabolites from oxidative, hydrolytic, and conjugative reactions in mice. J Agric Food Chem, 27, 4, 725-31.

Sabino, B. D., Torraca, T. G., et al. (2010). Development of a simple and low-cost enzymatic methodology for quantitative analysis of carbamates in meat samples of forensic interest. J Forensic Sci, 55, 3, 808-12.

Sannino, A. B., L.; Bandini, M. (2004). Application of liquid chromatography with electrospray tandem mass spectrometry to the determination of a new generation of pesticides in processed fruits and vegetables Journal of Chromatography A, 1036, 2, 161-169.

Sherma, J. (2000). Thin-layer chromatography in food and agricultural analysis. J Chromatogr A, 880, 1-2, 129-47.

Singh, S., Singhi, S., et al. (1997). Changing pattern of acute poisoning in adults: experience of a large North-west Indian hospital. Indian Pediatr., 32, 331-336. 
SINITOX. (2008). Sistema Nacional de Informacões Tóxico-Farmacológicas. Estatística Anual de casos de intoxicação e envenenamento; dados disponíveis até 2008., In http://www.fiocruz.br/sinitox, Retrieved 03/16/2011.

Soler, C. M., J.; Picó, Y. (2004). Liquid chromatography-electrospray quadrupole ion-trap mass spectrometry of nine pesticides in fruits Journal of Chromatography A, 1048, 1, 41-49.

Soler, C. M., J.; Picó, Y. (2005). Comparison of liquid chromatography using triple quadrupole and quadrupole ion trap mass analyzers to determine pesticide residues in oranges Journal of Chromatography A, 1067, 1-2, 115-125.

Soler, C. M., J.; Picó, Y. (2005). Routine application using single quadrupole liquid chromatography-mass spectrometry to pesticides analysis in citrus fruits Journal of Chromatography A, 1088, 1-2, 224-233.

Soler, C. P., Y. . (2007). Recent trends in liquid chromatography-tandem mass spectrometry to determine pesticides and their metabolites in food Trends in Analytical Chemistry, 26, 2, 103-115.

Soltaninejad, K., Faryadi, M., et al. (2007). Acute pesticide poisoning related deaths in Tehran during the period 2003-2004. J Forensic Leg Med, 14, 6, 352-4.

Somasundaram, D. J. \& Rajadurai, S. (1995). War and suicide in northern Sri Lanka. Acta Psychiatr Scand, 91, 1, 1-4.

Sri_Lanka. (1995). Sri Lankan Ministry of Health. Annual Health Bulletin. Ministry of Health, Colombo, Sri Lanka.

Suchan, P. P., J.; Hajslová, J.; Kocourek, V. (2004). Pressurized liquid extraction in determination of polychlorinated biphenyls and organochlorine pesticides in fish samples Analytica Chimica Acta, 520, 193.

Teixeira, H., Proenca, P., et al. (2004). Pesticide intoxications in the Centre of Portugal: three years analysis. Forensic Sci Int, 143, 2-3, 199-204.

Testud, F. \& Grillet, J. (2007). Insecticides organophosphorés, carbamates, pyréthinoides de synthèse et divers, Elsevier Masson, Paris.

Torres, C. M., Pico, Y., et al. (1996). Determination of pesticide residues in fruit and vegetables. J Chromatogr A, 754, 1-2, 301-31.

Van der Hoek, W., Konradsen, F., et al. (1998). Pesticide poisoning: a major health problem in Sri Lanka. Soc Sci Med, 46, 4-5, 495-504.

Vandekar, M., Plestina, R., et al. (1971). Toxicity of carbamates for mammals. Bull World Health Organ, 44, 1-3, 241-9.

Vougiouklakis, T., Boumba, V. A., et al. (2006). Fatal poisoning in the region of Epirus, Greece, during the period 1998-2004. J Clin Forensic Med, 13, 6-8, 321-5.

Vougiouklakis, T., Boumba, V. A., et al. (2005). Trends in suicide mortality in the deprived region of Epirus (north-west Greece) during the period 1998-2002. Med Sci Law, 45, 1,39-46.

Waiselfisz, J. (1998). Mapa da violência: os jovens do Brasil, UNESCO, Instituto Ayrton Senna, Garamond, Rio de Janeiro.

Wesseling, C., Aragon, A., et al. (2001). Hazardous pesticides in Central America. Int J Occup Environ Health, 7, 4, 287-94. 
WHO. (1990). WHO in collaboration with UNEP, Public Health Impact of Pesticide Used in Agriculture. Geneva.

WHO. (1991). Aldicarb. Environmental Health Criteria No. 21. International Programme on Chemical Safety. World Health Organization.

WHO. (2002). The World Health Report. Reducing Risks, Promoting Healthy Life. Geneve.

Yang, S. S., Goldsmith, A. I., et al. (1996). Recent advances in the residue analysis of Nmethylcarbamate pesticides. J Chromatogr A, 754, 1-2, 3-16.

Yusuf, H. R., Akhter, H. H., et al. (2000). Injury-related deaths among women aged 10-50 years in Bangladesh, 1996-97. Lancet, 355, 9211, 1220-4.

Zinn, C. (1995). South Pacific leads the world in rates of youth suicide. BMJ, 311, 830. 


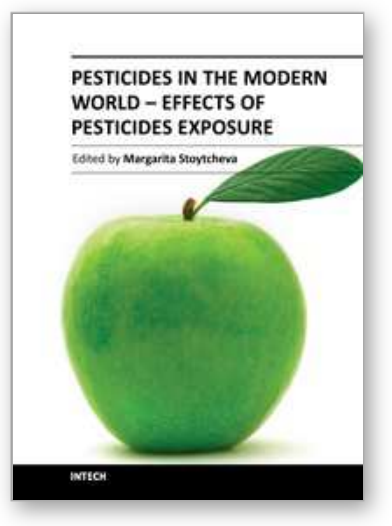

\author{
Pesticides in the Modern World - Effects of Pesticides Exposure \\ Edited by Dr. Margarita Stoytcheva
}

ISBN 978-953-307-454-2

Hard cover, 376 pages

Publisher InTech

Published online 12, September, 2011

Published in print edition September, 2011

The introduction of the synthetic organochlorine, organophosphate, carbamate and pyrethroid pesticides by 1950â $€^{\mathrm{TM}} \mathrm{s}$ marked the beginning of the modern pesticides era and a new stage in the agriculture development. Evolved from the chemicals designed originally as warfare agents, the synthetic pesticides demonstrated a high effectiveness in preventing, destroying or controlling any pest. Therefore, their application in the agriculture practices made it possible enhancing crops and livestockâ $\epsilon^{\mathrm{TM}} \mathrm{s}$ yields and obtaining higher-quality products, to satisfy the food demand of the continuously rising worldâ $€^{\mathrm{TM}} \mathrm{S}$ population. Nevertheless, the increase of the pesticide use estimated to 2.5 million tons annually worldwide since 1950 ., created a number of public and environment concerns. This book, organized in two sections, addresses the various aspects of the pesticides exposure and the related health effects. It offers a large amount of practical information to the professionals interested in pesticides issues.

\title{
How to reference
}

In order to correctly reference this scholarly work, feel free to copy and paste the following:

Bruno Sabino, Hannah Rozenbaum and Adriana Oliveira (2011). A Forensic View of Pesticide Poisonings in Brazil, Pesticides in the Modern World - Effects of Pesticides Exposure, Dr. Margarita Stoytcheva (Ed.), ISBN: 978-953-307-454-2, InTech, Available from: http://www.intechopen.com/books/pesticides-in-the-modernworld-effects-of-pesticides-exposure/a-forensic-view-of-pesticide-poisonings-in-brazil

\section{INTECH}

open science | open minds

\section{InTech Europe}

University Campus STeP Ri

Slavka Krautzeka 83/A

51000 Rijeka, Croatia

Phone: +385 (51) 770447

Fax: +385 (51) 686166

www.intechopen.com

\section{InTech China}

Unit 405, Office Block, Hotel Equatorial Shanghai

No.65, Yan An Road (West), Shanghai, 200040, China

中国上海市延安西路65号上海国际贵都大饭店办公楼 405 单元

Phone: +86-21-62489820

Fax: $+86-21-62489821$ 
(C) 2011 The Author(s). Licensee IntechOpen. This chapter is distributed under the terms of the Creative Commons Attribution-NonCommercialShareAlike-3.0 License, which permits use, distribution and reproduction for non-commercial purposes, provided the original is properly cited and derivative works building on this content are distributed under the same license. 